\title{
A systematic review of intervention programs that produced changes in speed and explosive strength in youth footballers
}

\author{
Marco Cossio-Bolaños (1), Ruben Vidal-Espinoza (2), Camilo Urra Albornoz (3), \\ Daniel Leite Portella (4), Sebastian Vega-Novoa (5), Jorge Mendez-Cornejo (1), Jose \\ Fuentes Lopez (6), Rossana Gomez-Campos (7)
}

(1) Departamento de Ciencias de la Actividad Física, Universidad Católica del Maule, Talca, Chile; (2) Universidad Católica Silva Henriquez, Santiago, Chile; (3) Escuela de Kinesiología, Facultad de Salud, Universidad Santo Tomás, Chile; (4) Programa de Mestrado em Inovação no Ensino Superior em Saúde, Universidade Municipal de São Caetano do Sul (Uscs), São Caetano do Sul, Brasil; (5) Universidad Autónoma de Chile, Talca, Chile; (6) Instituto de Investigación en Ciencias de la Educación (IICE), Universidad Nacional del Altiplano de Puno, Puno, Perú; (7) Departamento de Diversidad e Inclusividad Educativa, Universidad Católica del Maule, Talca, Chile.

This article is distributed under the terms of the Creative Commons Attribution Noncommercial License (CC BY-NC 4.0) which permits any noncommercial use, distribution, and reproduction in any medium, provided the original author(s) and source are credited.

\begin{abstract}
A soccer player should possess a reasonable level of different skills and abilities, so the playing position, level of training, style of play, physical and physiological demands can influence his performance. The objective was to identify the intervention programs that have been applied in search of generating positive effects on explosive strength and speed in young soccer players, as well as to identify the percentage of improvement among soccer players. A bibliographic study of systematic review was carried out. Following the Preferred Reporting Items for Systematic Reviews and Meta-analyses (PRISMA) statement, bibliographic searches were performed in the PubMed database. The following descriptors were used: Explosive Strength, soccer players, jump performance, CMJ, SJ, VJ, Plyometrics, power, speed, sprint, kicking speed, change of direction speed, soccer player, football and training, intervention. Articles were included only if they were original articles, studied populations of young soccer players and showed an intervention program related to explosive strength and speed. Six studies were identified that applied intervention programs to look for changes in speed and explosive strength in young soccer players. In the $5 \mathrm{~m}$ speed tests, significant changes were observed, improving from $(0.26$ to $0.53 \mathrm{~m} / \mathrm{s}), 10 \mathrm{~m}$ speed $(0.07$ to $0.27 \mathrm{~m} / \mathrm{s}), 20 \mathrm{~m}$ speed $(0.08$ to $1.92 \mathrm{~m} / \mathrm{s})$ and $40 \mathrm{~m}$ speed $(0.25$ to $0.62 \mathrm{~m} / \mathrm{s}$ ). In explosive strength, performance in the test squat jump SJ (4.1 to $8.6 \mathrm{~cm})$, countermovement jump CMJ (1.0 to $8.8 \mathrm{~cm})$, horizontal jump HJ $(12.17$ to $24.4 \mathrm{~cm})$ and vertical jump VJ (5.0 to $11.0 \mathrm{~cm})$. Speed and explosive strength are relevant components of athletic performance and can be improved through training programs that include 20 to $40 \mathrm{~min}$ sessions, training two to five times per week over a period of approximately 6 to 9 weeks.
\end{abstract}

Key Words: Training; speed; explosive strength; soccer; youth.

Soccer is a collective sport that reaches great popularity in the world, where it has about 200 million practitioners. ${ }^{1}$ It is characterized as a sport of intermittent efforts, in which sudden variations in both the intensity of the game and the type of actions or motor tasks occur continuously. $^{2}$ The ability to produce varied effective actions during a 90-minute game is associated with aerobic and anaerobic capacity. For example, performance in a soccer match depends on a variety of factors such as skills, tactical and physiological, physical and mental capacity of the players. ${ }^{2,3}$ In general, although the work in soccer is low intensity, a substantial amount of work is performed at high intensity, well known as maximal action. This work is often of great relevance to the performance of young soccer players. ${ }^{4}$ For example, plyometric training has been recommended in sports that require explosiveness, because it can increase skills such as vertical jumping ability and speed. ${ }^{5}$ In the specific case of Soccer, speed is of great importance, and includes 
changes of direction, acceleration and jumps. ${ }^{6}$ Also, explosive strength is one of the essential factors, since, strength training seems to be appropriate to improve ballistic movements in youth soccer players, reflecting in the performance of jumps, turns and speed runs. ${ }^{7,8}$ In fact, explosive strength, speed and agility are fundamental aspects for the performance of the soccer player, as they are the fundamental basis for performing different actions in matches, such as high-speed and short-duration movements, including, sudden or abrupt jumps, changes of direction, accelerations and decelerations Köklü et al. . $^{9-}$

${ }^{11}$ In this regard, in youth soccer, several studies have recently given emphasis on proposing and developing intervention programs with the purpose of improving performance in young soccer players. ${ }^{12-15}$ So studying the positive effects of training to improve explosive strength and speed in young soccer players is relevant. In fact, strength training and plyometrics are ways to seek the improvement of explosive strength and speed in a short time, aiming to increase explosive force production in athletes. This component is mainly determined by the strength and speed involved in the stretch-shortening cycle. ${ }^{16}$ Therefore, from this systematic review, we intend to answer the following question: What percentages of increase have been observed in speed and explosive strength from training programs in young soccer players?

\section{Materials and Methods}

A systematic study was performed according to the Preferred Reporting Items for Systematic Reviews and MetaAnalyses (PRISMA) statement that was developed to ensure the completeness of systematic reviews. ${ }^{17}$

\section{Eligibility criteria}

To achieve relevance in this systematic review, articles should include the following keywords: 1) Explosive strenght or strenght training or power or jump

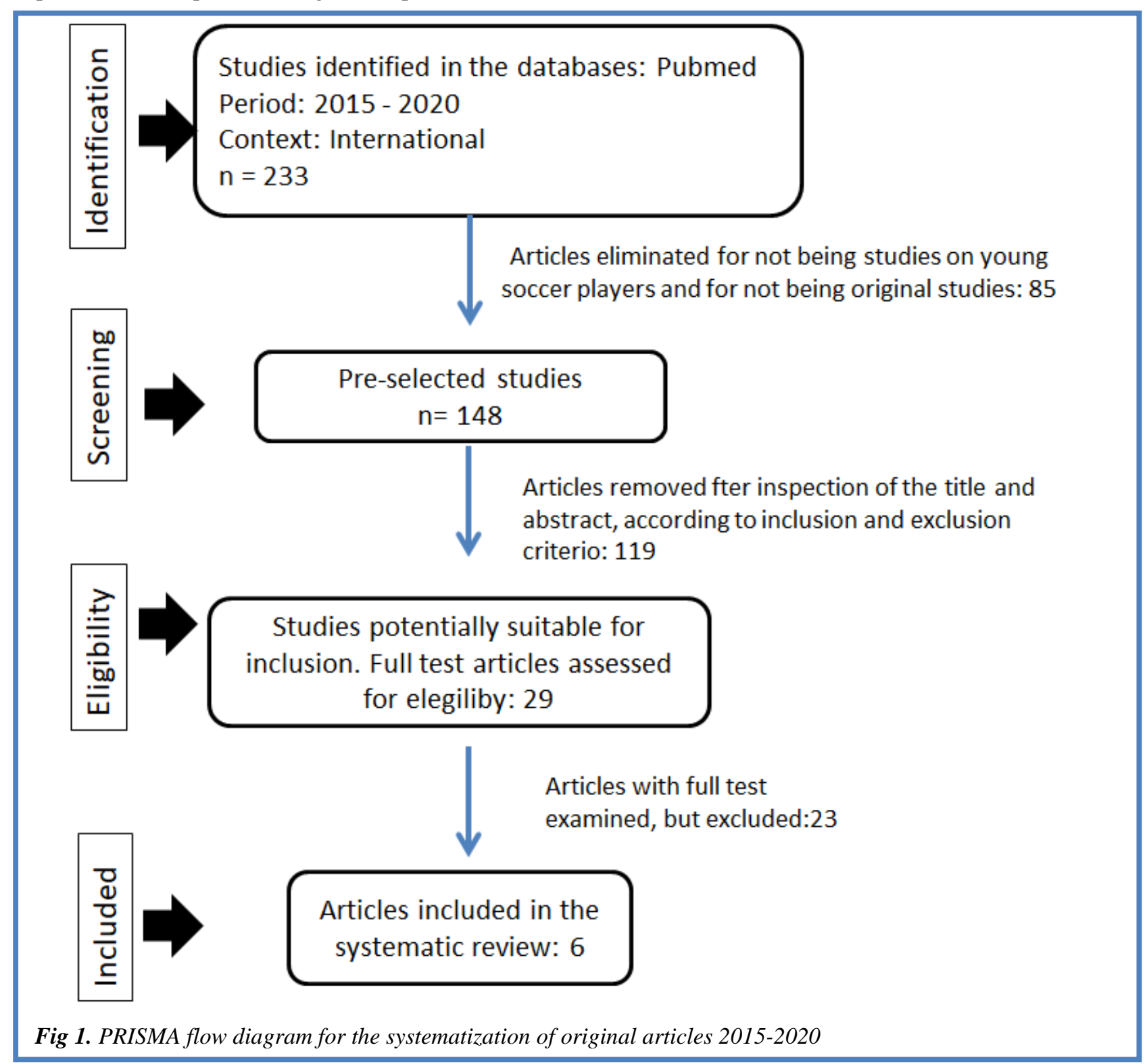




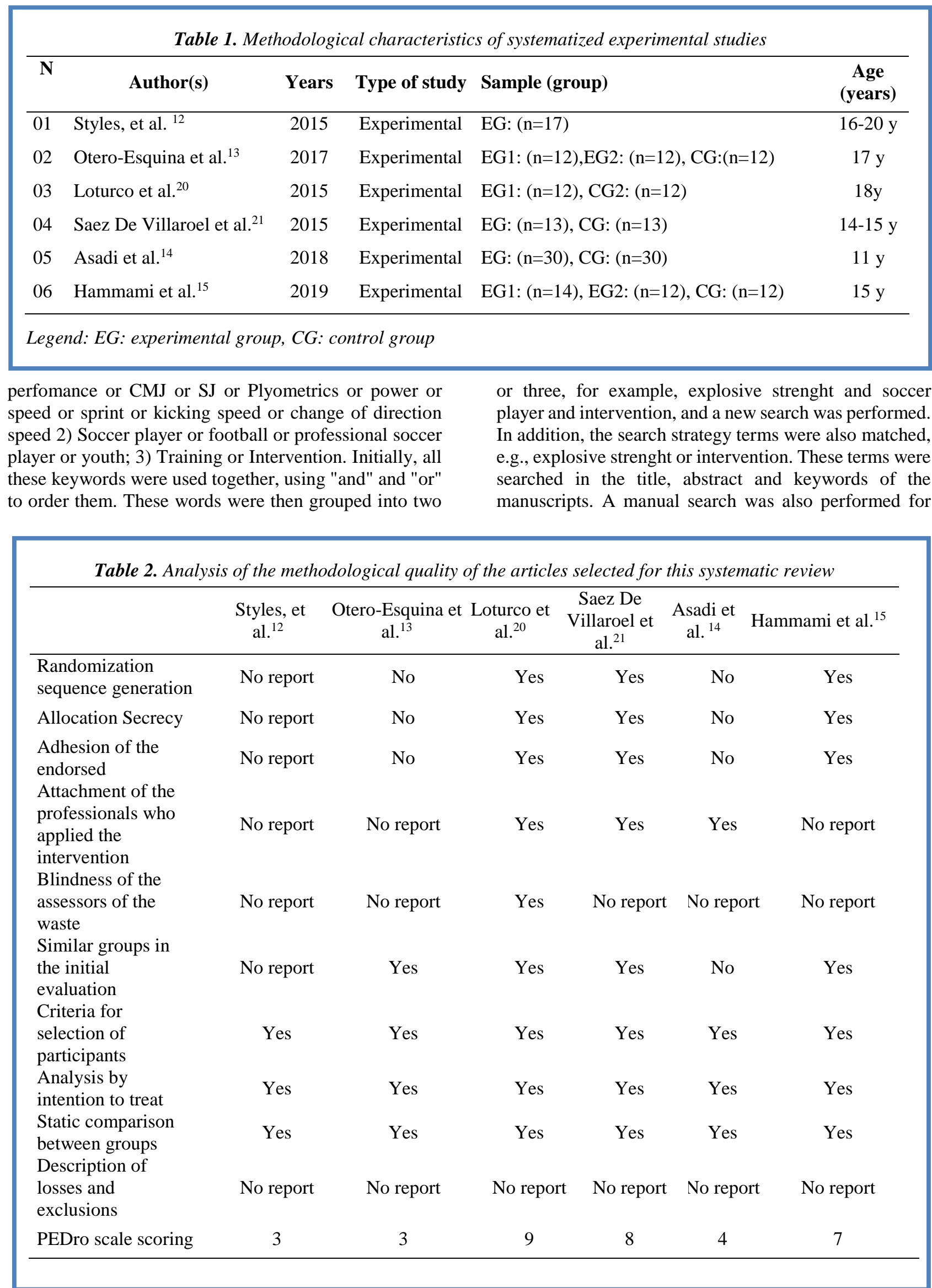


Table 3. Intervention programs used to improve speed and explosive strength in young soccer players

\begin{tabular}{|c|c|c|c|c|c|c|c|}
\hline $\mathbf{n}$ & Author(s) & Year & Activities & Intensity & $\begin{array}{c}\text { Frequency } \\
\text { x Week }\end{array}$ & $\begin{array}{l}\text { Session/day } \\
\text { (min) }\end{array}$ & $\begin{array}{c}\text { Duration } \\
\text { (weeks) }\end{array}$ \\
\hline 1 & Styles, et al. ${ }^{12}$ & 2015 & $\begin{array}{l}\text { Maximum strength } \\
\text { exercises, squats and } \\
\text { sprints }\end{array}$ & $85-90 \% 1 \mathrm{MR}$ & 2 & NS & 6 \\
\hline 2 & $\begin{array}{l}\text { Otero-Esquina et } \\
\text { al. }{ }^{13}\end{array}$ & 2017 & $\begin{array}{l}\text { Maximal strength, } \\
\text { squats, } \\
\text { sprints }\end{array}$ & $\begin{array}{c}40-50 \% \\
1 \mathrm{RM}\end{array}$ & 2 & NS & 7 \\
\hline 3 & Loturco et al. ${ }^{20}$ & 2015 & $\begin{array}{l}\text { Vertical jump and } \\
\text { horizontal jump }\end{array}$ & NS & $4-5$ & 20min & 3 \\
\hline 4 & $\begin{array}{l}\text { Saez De Villaroel } \\
\text { et al. }{ }^{21}\end{array}$ & 2015 & $\begin{array}{l}\text { Squats, lunges, jumping } \\
\text { hurdles, } \\
\text { dribbles }\end{array}$ & NS & 2 & 40min & 9 \\
\hline 5 & Asadi et al. ${ }^{14}$ & 2018 & $\begin{array}{l}\text { Plyometrics, deep box } \\
\text { jumps }\end{array}$ & NS & $2-3$ & 30-40min & 6 \\
\hline 6 & Hammami et al. ${ }^{15}$ & 2019 & $\begin{array}{l}\text { Maximum strength, } \\
\text { plyometrics, jumps with } \\
\text { fall }\end{array}$ & $70-90 \% 1 \mathrm{RM}$ & 2 & 40min & 8 \\
\hline
\end{tabular}

articles that were not in the database searched, e.g., studies cited by other manuscripts. In the case of some studies that included systematic reviews, they were excluded from the analysis. The search was limited to articles that investigated young soccer players. In addition, articles that fit the eligibility criteria of this study, but that could not be accessed in full (because they were not available electronically or in hard copy or were requested from the authors but not submitted) were also excluded.

\section{Search Strategy}

The initial search strategy was to identify articles investigating the effects of intervention programs on youth soccer players. An electronic search was conducted in the database: PubMed. The electronic search was conducted over a period of four weeks from January 13 to February 07, 2020. Targeted searches in the most cited journals and authors and in the reference lists of the articles ensured that all relevant articles were located. The basis for the search strategy was considered using the components of the PICOS (Population, Interventions, Comparators, Outcomes, and Study design) tool. Being P: Young soccer players participating in intervention programs; I: Intervention programs that seek to generate effects on explosive strength and speed; $\mathrm{C}$ : Present an experimental group or two experimental groups subjected to different types of activity, which can be compared before and after, with or without control group; O: Have an evaluation before and after the period elapsed with the intervention to demonstrate the efficacy and applicability of the program on explosive strength (CMJ, HJ and VJ) and speed ( $5 \mathrm{~m}, 10 \mathrm{~m}, 20 \mathrm{~m}$ and $40 \mathrm{~m}$ ); S: experimental studies. Studies were evaluated according to defined criteria for inclusion or exclusion from the review.

\section{Methodological quality}

Methodological quality was assessed independently by two reviewers (MC, RG) who analyzed the studies selected for this systematic review and resolved disagreements in the analysis by consensus. The methodological quality of the studies was reviewed using the PEDro scale based on the Delphi list. ${ }^{18,19}$ This scale has 10 scoring questions, and each criterion is scored according to its presence (one point) or absence (zero points) in the study in question. To assess the methodological quality of the selected studies, the following items were considered: generation of the randomization sequence; confidentiality of the allocation; blinding of those evaluated; blinding of the professionals and evaluators who applied the intervention/evaluation; blinding of the evaluators of the study results; similar groups at baseline; participant selection criteria; intention-to-treat analysis; statistical comparison between groups; description of losses and exclusions.

\section{Data extraction and analysis}

Data from the articles were extracted in their entirety using a structured script that included the following items: sample (age of study participants), research design, duration and type of intervention performed in the study, effects (positive or not) found, limitations and recommendations. Data extraction was performed by one reviewer, and the second reviewer checked the data extraction to ensure that the data collected were accurate and complete. The results of the articles were presented descriptively using means, standard deviations and 
percentages (\%). These indicators allowed quantifying in a descriptive way the \% increases in explosive strength and speed.

\section{Results}

In the study selection process observed according to the PRISMA flowchart in Figure 1, the process developed. A total of 233 studies were identified worldwide, which were considered as possible potential studies for systematization. After being reviewed, 148 studies were eliminated because they were not original studies and were not on young soccer players. In the next stage, the titles and abstracts were read according to the inclusion and exclusion criteria, and 119 articles were eliminated. In the third stage, of the 29 eligible studies that were read in their entirety, 23 that were not experimental were eliminated, leaving 6 articles that were finally considered in this review. After careful reading of the articles in their entirety, 6 studies (Table 1) were selected to compose this systematic review that met all the criteria determined by the study. The six studies were designed as experimental studies (with and without experimental group). Table 2 shows the results of the quality analysis of the articles. All the studies selected for this systematic review presented participant selection criteria and included statistical comparison between groups. However, only $50 \%$ of them presented blinding of the evaluated, showing confidentiality in the allocation of participants. Likewise, only one study (16.7\%) considered blinding of the professional who applied the intervention, hiding the identity of the group assignments from the researchers who collected and analyzed the variables of interest. Regarding the evaluation of methodological quality through the PEDro scale, ${ }^{18}$ the studies that showed the highest scores Loturco et al. ${ }^{20}$ (9 points), Saez De Villaroel et al. ${ }^{21}$ (8 points) and Hammami et al. ${ }^{15}$ (7 points) on this scale. Thus, although the studies in this review present consistent and positive results on the effect of the intervention on explosive strength and speed, they should be interpreted with caution due to the limitations presented by the methodology of the studies in this systematic review according to the PEDro scale. ${ }^{18}$ The intervention programs applied by the six studies are shown in Table 3. All the studies applied intervention programs based on maximal strength, plyometric and sprint exercises. The intervention programs generally performed their interventions 2 to 5 times per week, with an approximate duration of 20 to $40 \mathrm{~min}$ per session and with a duration of 6 to 9 weeks of intervention. Tables 4 and 5 show the changes observed in speed and explosive strength in young soccer players. In general, positive changes were observed in all speed tests, except in the study by Otero-Esquina et al., ${ }^{13}$ where there was no change in the $10 \mathrm{~m}$ speed test. For example, in the $5 \mathrm{~m}$ speed test there was an increase from 5.7 to $11.9 \%(0.26$ to $0.53 \mathrm{~m} / \mathrm{s}$ ), in the $10 \mathrm{~m}$ speed test performance increased from 0.52 to $5.05 \%(0.03$ to $0.27 \mathrm{~m} / \mathrm{s})$, in the $20 \mathrm{~m}$ speed from 0.44 to $36.7 \%(0.03$ to $1.92 \mathrm{~m} / \mathrm{s})$ and in the $40 \mathrm{~m}$ speed improved from 3.59 to $9.19 \%(0.25$ to $0.62 \mathrm{~m} / \mathrm{s})$, respectively. In the case of the studies that had a control group, minimal variations were observed and in some even a decrease in speed, as in the Saez De Villaroel study (from -1 to -3.82\%). In explosive strength, the five studies showed significant changes and gains in the groups subjected to the intervention program, in four explosive strength tests. For example, in the SJ they increased from 11.1 to $25.4 \%$ (4.1 to $8.6 \mathrm{~cm}$ ), in the CMJ they increased from 2.3 to $23.03 \%$ (1.0 to $8.8 \mathrm{~cm})$, in the VJ they improved from 15.15 to $27.09 \%$ (5.0 to $11.0 \mathrm{~cm}$ ) and finally, in the HJ, they increased 4.9 to $9.9 \%$ (12.17 to $24.4 \mathrm{~cm})$. In the case of the $\mathrm{CMJ}$, in the control groups of the studies by Otero-Esquina et al. ${ }^{13}$ and Loturco et al. ${ }^{20}$, no changes were observed in the post-test. In the case of the other studies with a control group, the variations observed were $3.86 \%$ and $1.84 \%$ for the SJ and CMJ in the study by Hammami et al. ${ }^{15}$ and 3.23 to $6.09 \%$ for the VJ in the study by Asadi et al. ${ }^{14}$

\section{Discussion}

The results of the systematization have shown that there were positive changes in speed and explosive strength tests in young soccer players. The intervention programs were generally applied to youngsters from 11 to 20 years old, whose training activities were based on maximum strength, plyometric and sprint exercises. These programs were carried out between 2 to 5 times per week, with an approximate duration between 20 to $40 \mathrm{~min}$ per session and between 3 to 9 weeks of intervention. After systematization of the six studies, positive effects on speed and explosive strength were observed. For example, in the $5 \mathrm{~m}$ speed tests, significant changes were observed, improving from ( 0.26 to $0.53 \mathrm{~m} / \mathrm{s}), 10 \mathrm{~m}$ speed ( 0.03 to $0.27 \mathrm{~m} / \mathrm{s}), 20 \mathrm{~m}$ speed $(0.03$ to $1.92 \mathrm{~m} / \mathrm{s})$ and $40 \mathrm{~m}$ speed $(0.25$ to $0.62 \mathrm{~m} / \mathrm{s})$. In explosive strength, the results of the studies have shown positive changes in the four tests. Performance in the SJ squat jump test improved from 4.1 to $8.6 \mathrm{~cm}$, in the CMJ countermovement jump (1.0 to $8.8 \mathrm{~cm}$ ), in the $\mathrm{HJ}$ horizontal jump (12.17 to $24.4 \mathrm{~cm})$ and in the $\mathrm{VJ}$ vertical jump $(5.0$ to $11.0 \mathrm{~cm})$, respectively. In fact, the training of sprints (at high speeds), maximum strength exercises and plyometrics seem to be crucial to obtain positive adaptations in the performance of young soccer players, since systematized studies have evidenced positive changes in the improvement of speed and explosive strength tests. In general, explosive strength is necessary to accelerate and maintain a maximum speed in sprint performance, for this purpose a great rigidity in the legs is required to produce a high running speed ${ }^{7}$. This is achieved during training due to a variety of motor actions involving propulsive force, forms of muscle contraction, speed changes, agility, among others. In terms of performance, greater tendon stiffness plays a fundamental role in the rapid transmission of force from the muscles to the skeletal system, ${ }^{22}$ and consequently allows greater velocity of the muscle-tendon units, positively 


\section{Programs for speed and explosive strength in youth footballers}

Eur J Transl Myol 31 (3): 9692, 2021 doi: 10.4081/ejtm.2021.9692

influencing stretch-shortening exercises. ${ }^{23}$ Although in general, these results depend on many factors, due to the large number of variables that have to do with the quantity and quality of the training load, ${ }^{24}$ as well as the degree of motivation of the players. In general, most scientists who analyze and design intervention programs

Table 4. Changes observed in speed tests (5m,10m, 20m and 40m), according to intervention programs applied

\begin{tabular}{|c|c|c|c|c|c|c|c|c|c|c|}
\hline \multirow{2}{*}{ Author(s) } & \multirow{2}{*}{ Groups } & \multirow{2}{*}{ Evaluation } & \multicolumn{2}{|c|}{ V $5 m$} & \multicolumn{2}{|c|}{ V 10m } & \multicolumn{2}{|c|}{ V 20m } & \multicolumn{2}{|c|}{ V 40m } \\
\hline & & & $\mathrm{X} \pm \mathrm{SD}$ & $\%$ & $\mathrm{X} \pm \mathrm{SD}$ & $\%$ & $\mathrm{X} \pm \mathrm{SD}$ & $\%$ & $\mathrm{X} \pm \mathrm{SD}$ & $\%$ \\
\hline \multirow{2}{*}{ Styles, et al. ${ }^{12}$} & \multirow{2}{*}{ EG } & Pre-Test & $4.50 \pm 0.04$ & \multirow{2}{*}{0.26 (5.77\%) } & $5.46 \pm 0.05$ & 0.15 & $6.47 \pm 0.07$ & \multirow{2}{*}{$0.08(1.23 \%)$} & -- & \multirow{2}{*}{--} \\
\hline & & Post-Test & $4.76 \pm 0.03$ & & $5.61 \pm 0.05$ & (2.74\%) & $6.55 \pm 0.05$ & & -- & \\
\hline \multirow{7}{*}{$\begin{array}{l}\text { Otero-Esquina et } \\
\qquad \text { al. }^{13}\end{array}$} & \multirow{3}{*}{ EG1 } & Pre-Test & -- & \multirow{3}{*}{--} & $5.88 \pm 0.06$ & \multirow{3}{*}{$0.00(0.0 \%)$} & $6.68 \pm 0.07$ & & -- & \multirow{3}{*}{--} \\
\hline & & & & & & & & $0.03(0.44 \%)$ & & \\
\hline & & Post-Test & -- & & $5.88 \pm 0.05$ & & $6.71 \pm 0.08$ & & -- & \\
\hline & \multirow{2}{*}{ EG2 } & Pre-Test & -- & \multirow{2}{*}{--} & $5.84 \pm 0.05$ & \multirow{2}{*}{$\begin{array}{c}0.07 \\
(1.19 \%)\end{array}$} & $6.71 \pm 0.09$ & \multirow{2}{*}{$\begin{array}{c}0.11 \\
(1.61 \%)\end{array}$} & -- & \multirow{2}{*}{-- } \\
\hline & & Post-Test & -- & & $5.91 \pm 0.05$ & & $6.82 \pm 0.11$ & & -- & \\
\hline & & Pre-Test & & & $5.74 \pm 0.04$ & & $6.57 \pm 0.05$ & & -- & \\
\hline & CG & Post-Test & & & $5.74 \pm 0.05$ & $0.00(0.0 \%)$ & $6.57 \pm 0.05$ & $0.00(0.0 \%)$ & -- & -- \\
\hline & & Pre-Test & -- & & $5.73 \pm 0.21$ & 0.03 & $6.69 \pm 0.27$ & & -- & \\
\hline & GEIVJ & Post-Test & -- & -- & $5.76 \pm 0.24$ & $(0.52 \%)$ & $6.90 \pm 0.23$ & $0.09(1.30 \%)$ & -- & -- \\
\hline Loturco et.al. ${ }^{20}$ & & & & & & & & & & \\
\hline & & Pre-Test & -- & & $5.67 \pm 0.20$ & 0.13 & $6.64 \pm 0.20$ & & -- & \\
\hline & 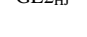 & Post-Test & -- & & $5.80 \pm 0.21$ & $(0.52 \%)$ & $6.69 \pm 0.23$ & $0.00(0.747)$ & -- & \\
\hline & FC. & Pre-Test & $6.17 \pm 0.1$ & $058(94 \%)$ & $5.34 \pm 0.1$ & 0.27 & -- & & -- & \\
\hline Saez De Villaroel & El & Post-Test & $6.75 \pm 0.1$ & $0.00(5,4 / 0)$ & $5.61 \pm 0.1$ & (5.05\%) & -- & -- & -- & - \\
\hline et al..$^{21}$ & $C \Gamma$ & Pre-Test & $6.25 \pm 0.10$ & 0.23 & $5.23 \pm 0.10$ & 0.05 & & & & \\
\hline & 政 & Post-Test & $6.02 \pm 0.10$ & $(-3.82 \%)$ & $5.18 \pm 0.10$ & $(-1.0 \%)$ & & & & \\
\hline & EG1 & Pre-Test & -- & & -- & & $4.46 \pm 0.85$ & & -- & \\
\hline & PrePHV & & & -- & & -- & & 0.19 (4.26\%) & & -- \\
\hline & group & Post-Test & -- & & -- & & $4.65 \pm 0.75$ & & -- & \\
\hline & EG2 Mid & Pre-Test & -- & & -- & & $5.23 \pm 0.48$ & & -- & \\
\hline & PHV group & Post-Test & -- & -- & -- & -- & & $0.43(8.2 \%)$ & $\ldots$ & -- \\
\hline & & - & & & & & $0.00-0.40$ & & & \\
\hline & EG3 & Pre-Test & -- & & -- & & $5.22 \pm 0.52$ & & -- & \\
\hline & Post PHV & & & -- & & -- & & 1.92 (36.7\%) & & -- \\
\hline Acadi at 14 & group & Post-Test & -- & & -- & & $7.14 \pm 0.4$ & & -- & \\
\hline 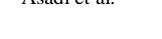 & CG1 & Pre-Test & -- & & -- & & $4.23 \pm 0.77$ & & -- & \\
\hline & PrepHV & & & -- & & -- & & 0.02 (0.47\%) & & -- \\
\hline & group & Post-Test & -- & & -- & & $4.25 \pm 0.80$ & & -- & \\
\hline & CG2 & Pre-Test & -- & & -- & & $5.31 \pm 0.37$ & & -- & \\
\hline & Mid PHV & & & -- & & -- & & $0.08(1.48 \%)$ & & -- \\
\hline & group & Post-Test & -- & & -- & & $5.39 \pm 0.33$ & & -- & \\
\hline & CG3 & Pre-Test & -- & & -- & & $6.47 \pm 0.68$ & & -- & \\
\hline & Post PHV & & & -- & & -- & & $0.10(1.52 \%)$ & & -- \\
\hline & group & Post-Test & -- & & -- & & $6.57 \pm 0.59$ & & -- & \\
\hline & FCI & Pre-Test & $4.42 \pm 0.04$ & $0=-2,00$ & -- & & -- & & $6.74 \pm 0.22$ & 0.62 \\
\hline & 501 & Post-Test & $4.95 \pm 0.17$ & (1.5) & -- & & -- & & $7.36 \pm 0.17$ & (9.19\%) \\
\hline & & Pre-Test & $4.62 \pm 0.05$ & & -- & & -- & & $6.95 \pm 0.26$ & 0.25 \\
\hline Hammami et al. ${ }^{13}$ & EG2 & Post-Test & $5.00 \pm 0.09$ & 0.38 (8.22\%) & -- & -- & -- & -- & $7.20 \pm 0.26$ & (3.59\%) \\
\hline & & Pre-Test & $4.85 \pm 0.06$ & & & & & & $6.84 \pm 0.32$ & 0.11 \\
\hline & - & Post-Test & $4.62 \pm 0.04$ & $0.23(4 . / 4 \%)$ & & & & & $6.95 \pm 0.33$ & $(1.60 \%)$ \\
\hline
\end{tabular}

Legend: EG: experimental group, CG: control group, V: Velocity, HJ: Horizontal Jump, VJ: Vertical Jump, PHV: peak height velocity, SD: Standard deviation 
Programs for speed and explosive strength in youth footballers

Eur J Transl Myol 31 (3): 9692, 2021 doi: 10.4081/ejtm.2021.9692

Table 5. Changes observed in explosive strength (SJ, CMJ, SV and SH), according to intervention programs applied

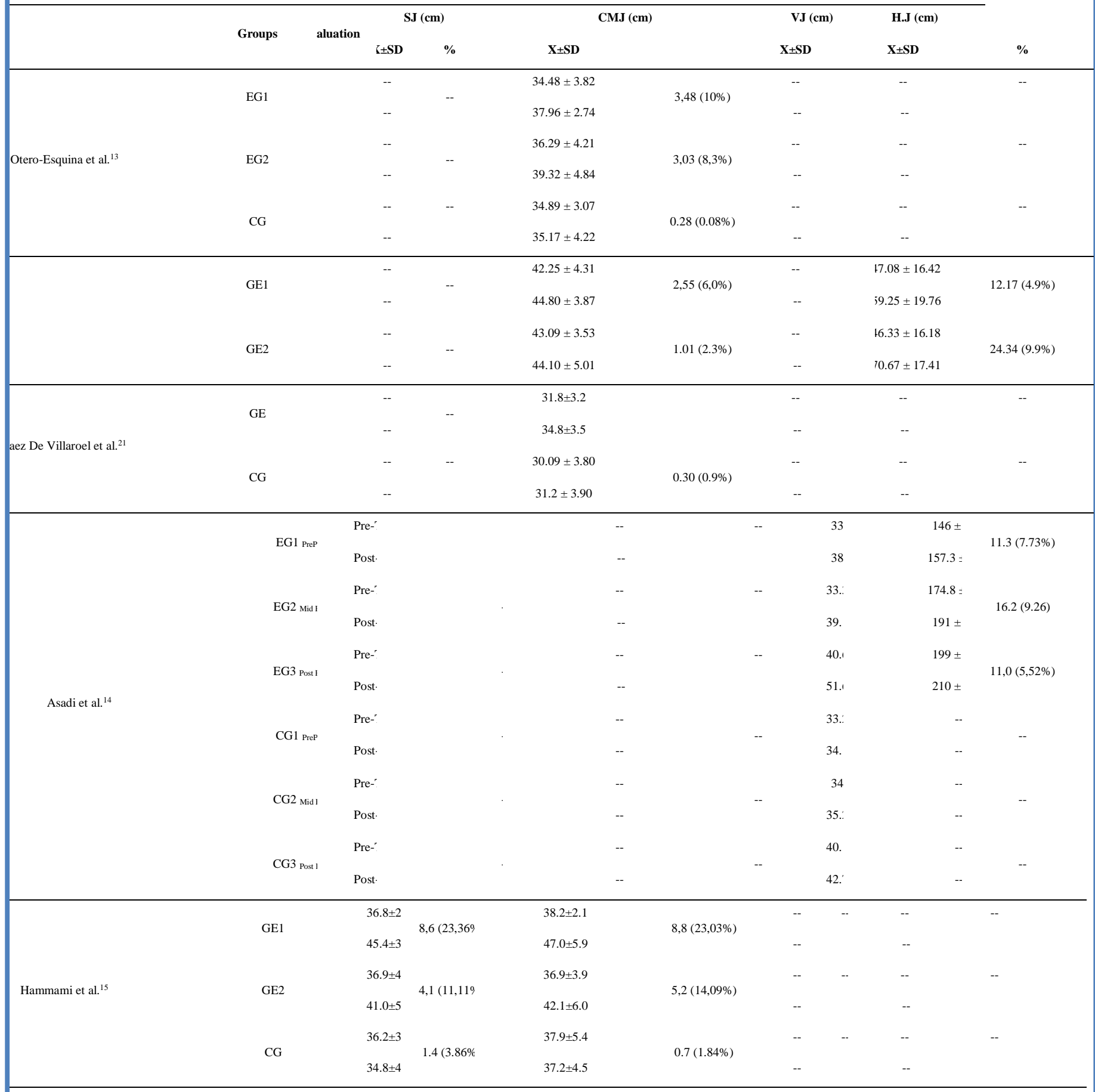

Legend: EG: experimental group, CG: control group, V: Velocity, HJ: Horizontal Jump, VJ: Vertical Jump, PHV: peak height velocity, SD: Standard deviation

to improve the physical performance of young soccer players have proposed short-term programs of 4 to 8 weeks with a frequency of $2 \mathrm{x}$ weekly, ${ }^{7,21,25}$ and even up to 12 weeks. ${ }^{26}$ These proposals appear to be consistent with systematized studies, since they are within the parameters established by previous studies. Therefore, the training of youth physical performance capabilities promotes neuro-muscular development and adequate muscular adaptation not only to avoid the risk of sports injuries, but also to create a solid foundation for athletes to achieve high performance in the future. In that sense, in an attempt to provide relevant information for professionals working with young soccer players, this systematic review provides significant elements to 
propose and develop intervention programs to improve speed and explosive strength in young soccer players from 11 to 20 years of age. The increase and improvement observed in the systematized studies can also serve as a reference and as a model for proposing new intervention programs. The intervention programs analyzed in this study are directly applicable to youth soccer categories of clubs in general. This implies that young soccer players should use submaximal loads according to their growth and biological maturation process to develop form and technique in a variety of exercises during training. ${ }^{27}$ For example, the American Academy of Pediatrics does not endorse the use of continuous maximal lifts for strength training in youth ${ }^{28}$, so all programs involving the use of weight lifting and plyometrics should be individualized based on age, maturity status, personal goals and objectives. ${ }^{28}$ Consequently, this study presented some limitations related to systematized research, given that not all reported the time (minutes) used to develop the intervention programs, as well as the frequency per week and the intensity at which they trained. In addition, the protocols used to evaluate speed and explosive strength vary among studies, which may bias the results obtained, and most studies do not describe the sociodemographic characteristics of each country (country where the study was conducted). This information is relevant, since coaches working with youth training programs can consider these indicators derived from these populations to approximate the generalization of the results to other contexts. This is because in countries where there is no mass soccer practice it may not be relevant for other populations. The information provided in this study can serve as a baseline for future comparisons, for implementing future training programs in youth soccer players, and as evidence for researchers to contrast with future studies. This systematic review compiled scientific evidence that can help professionals working in youth soccer, since speed and explosive strength are relevant components of athletic performance, reaching percentage increases in speed tests from 1.19 to $36.7 \mathrm{~m} / \mathrm{s}$ and in explosive strength from 2.3 to $27.0 \%$. The results suggest to developing training programs in young soccer players with a frequency of 2 to 5 times per week, with sessions of 20 to 40 minutes and in a period of approximately 3 to 9 weeks.

\section{List of acronyms}

CMJ - Counter Movement Jump

PEDro - Physiotherapy Evidence Database

PRISMA - Preferred Reporting Items for Systematic

Reviews and Meta-analyses

SJ - Squat Jump

VJ - Vertical Jump

\section{Authors contributions}

MCB, DLP, RGC: conception, design, drafting of the manuscript, analysis and interpretation of the data, critical review and final approval of the version to be published, agreement to be responsible for all aspects of the work to ensure that issues related to the accuracy or completeness of any part of the work are adequately investigated and resolved; MCB, RGC, JMC, JFL: critical review of important intellectual content; and final approval of the version to be published; RVE, SVN, JMC, JFL: systematization of the studies, critical review and final approval of the version to be published.

\section{Acknowledgments}

A special acknowledgement of appreciation goes to the team of professionals in the municipal schools of Talca for their collaboration and participation in the data collection process.

\section{Funding}

This research did not receive any specific grant from funding agencies in the public, commercial, or not-forprofit sectors.

\section{Conflict of Interest}

The authors declare no competing interests.

\section{Ethical Publication Statement}

We confirm that we have read the Journal's position on issues involved in ethical publication and affirm that this report is consistent with those guidelines.

\section{Corresponding Author}

Rossana Gómez Campos, PhD, Av. San Miguel s/n Talca, Chile.

ORCID iD: 0000-0001-6509-5707

E-mail: rossaunicamp@gmail.com

E-mails and ORCID iD of co-authors

Marco Cossio-Bolaños: mcossio1972@hotmail.com ORCID iD https://orcid.org/0000-0001-7230-9996

Ruben Vidal-Espinoza: rvidale@gmail.com

ORCID iD: 0000-0002-8593-5248

Camilo Urra-Albornoz: c.urra.albornoz@gmail.com ORCID iD: 0000-0000-0002-5936-359X

Daniel Leite Portella: daniel.portella@prof.uscs.edu.br ORCID iD: https://orcid.org/0000-0002-5259-9049

Sebastian Vega-Novoa: sveganovoa@gmail.com

Jorge Mendez-Cornejo: jmendez@ucm.cl

ORCID iD: 0000-0000-0002-3925-170X

Jose Fuentes Lopez: jofuelo@hotmail.com

ORCID iD: https://orcid.org/0000-0002-6699-1439

\section{References}

1. Alexandre D, da Silva CD, Hill-Haas S, Wong del P, Natali AJ, De Lima JR, Bara Filho MG, Marins JJ, Garcia ES, Karim C. Heart rate monitoring in soccer: interest and limits during competitive match play and training, practical application. J Strength Cond Res. 2012 Oct;26(10):2890-906. doi: 10.1519/JSC.0b013e3182429ac7. 
2. Stølen T, Chamari K, Castagna C, Wisløff U. Physiology of soccer: an update. Sports Med. 2005;35(6):501-36. doi: 10.2165/00007256200535060-00004.

3. Mara JK, Thompson KG, Pumpa KL, Morgan S. The acceleration and deceleration profiles of elite female soccer players during competitive matches. J Sci Med Sport. 2017 Sep;20(9):867-872. doi: 10.1016/j.jsams.2016.12.078. Epub 2017 Jan 24.

4. Bradley PS, Sheldon W, Wooster B, Olsen P, Boanas P, Krustrup P. High-intensity running in English FA Premier League soccer matches. J Sports Sci. 2009 Jan 15;27(2):159-68. doi: 10.1080/02640410802512775.

5. Sedano Campo S, Vaeyens R, Philippaerts RM, Redondo JC, de Benito AM, Cuadrado G. Effects of lower-limb plyometric training on body composition, explosive strength, and kicking speed in female soccer players. J Strength Cond Res. 2009 Sep;23(6):1714-22. doi: 10.1519/JSC.0b013e3181 b3f537.

6. Cherif M, Said M, Chaatani S, Nejlaoui O, Gomri D, Abdallah A. The effect of a combined highintensity plyometric and speed training program on the running and jumping ability of male handball players. Asian J Sports Med. 2012 Mar;3(1):21-8. doi: 10.5812/asjsm.34721.

7. Chelly MS, Fathloun M, Cherif N, Ben Amar M, Tabka Z, Van Praagh E. Effects of a back squat training program on leg power, jump, and sprint performances in junior soccer players. J Strength Cond Res. 2009; 23: 2241-2249.

8. Di Giminiani R, Visca C. Explosive strength and endurance adaptations in young elite soccer players during two soccer seasons. PLoS One. 2017 Feb 13;12(2):e0171734. doi: 10.1371/journal.pone. 0171734.

9. Köklü Y, Alemdaroğlu U, Özkan A, Koz M, Ersöz G. The relationship between sprint ability, agility and vertical jump performance in young soccer players. Science \& Sports. 2015; 30(1): e1-e5. doi: 10.1016/j.scispo.2013.04.006.

10. DeWeese B, Nimphius S. Program design and technique for speed and agility training. In: Essentials of strength training and conditioning. Champaign: Human Kinetics. 2016; 521-558.

11. Nygaard Falch H, Guldteig Rædergård $H$, van den Tillaar R. Effect of Different Physical Training Forms on Change of Direction Ability: a Systematic Review and Meta-analysis. Sports Med Open. 2019 Dec 19;5(1):53. doi: 10.1186/s40798-019-0223-y.

12. Styles WJ, Matthews MJ, Comfort P. Effects of Strength Training on Squat and Sprint Performance in Soccer Players. J Strength Cond Res. 2016 Jun;30(6):1534-9. doi: 10.1519/JSC.000000000000 1243.

13. Otero-Esquina C, de Hoyo Lora M, Gonzalo-Skok Ó, Domínguez-Cobo S, Sánchez H. Is strength- training frequency a key factor to develop performance adaptations in young elite soccer players? Eur J Sport Sci. 2017 Nov;17(10):12411251. doi: 10.1080/17461391.2017.1378372. Epub 2017 Sep 24.

14. Asadi A, Ramirez-Campillo R, Arazi H, Sáez de Villarreal E. The effects of maturation on jumping ability and sprint adaptations to plyometric training in youth soccer players. J Sports Sci. 2018 Nov;36(21):2405-2411. doi: 10.1080/02640414. 2018.1459151. Epub 2018 Apr 3.

15. Hammami M, Gaamouri N, Shephard RJ, Chelly MS. Effects of Contrast Strength vs. Plyometric Training on Lower-Limb Explosive Performance, Ability to Change Direction and Neuromuscular Adaptation in Soccer Players. J Strength Cond Res. 2019 Aug;33(8):2094-2103. doi: 10.1519/JSC. 0000000000002425.

16. Potach D, Chu D. Program design and technique for plyometric training. In: NSCA, editor. Essentials of strength training and conditioning. Human Kinetics. 2016; 471-520.

17. Liberati A, Altman DG, Tetzlaff J, Mulrow C, Gøtzsche PC, Ioannidis JP, Clarke M, Devereaux PJ, Kleijnen J, Moher D. The PRISMA statement for reporting systematic reviews and meta-analyses of studies that evaluate health care interventions: explanation and elaboration. PLoS Med. 2009 Jul 21;6(7):e1000100. doi: 10.1371/journal.pmed. 1000100. Epub 2009 Jul 21.

18. de Morton NA. The PEDro scale is a valid measure of the methodological quality of clinical trials: a demographic study. Aust J Physiother. 2009;55(2):129-33. doi: 10.1016/s0004-9514(09) 70043-1.

19. Verhagen AP, de Vet HC, de Bie RA, Kessels AG, Boers M, Bouter LM, Knipschild PG. The Delphi list: a criteria list for quality assessment of randomized clinical trials for conducting systematic reviews developed by Delphi consensus. J Clin Epidemiol. 1998 Dec;51(12):1235-41. doi: 10.1016/s0895-4356(98)00131-0.

20. Loturco I, Pereira LA, Kobal R, Zanetti V, Kitamura K, Abad CC, Nakamura FY. Transference effect of vertical and horizontal plyometrics on sprint performance of high-level U-20 soccer players. J Sports Sci. 2015;33(20):2182-91. doi: 10.1080/02640414.2015.1081394. Epub 2015 Sep 21.

21. Sáez de Villarreal E, Suarez-Arrones L, Requena B, Haff GG, Ferrete C. Effects of Plyometric and Sprint Training on Physical and Technical Skill Performance in Adolescent Soccer Players. J Strength Cond Res. 2015 Jul;29(7):1894-903. doi: 10.1519/JSC.0000000000000838.

22. Mersmann F, Bohm S, Schroll A, Marzilger R, Arampatzis A. Athletic training affects the uniformity of muscle and tendon adaptation during 


\section{Programs for speed and explosive strength in youth footballers}

Eur J Transl Myol 31 (3): 9692, 2021 doi: 10.4081/ejtm.2021.9692

adolescence. J Appl Physiol (1985). 2016 Oct 1;121(4):893-899. doi: 10.1152/japplphysiol.00 493.2016. Epub 2016 Sep 1.

23. Horita T, Komi PV, Hämäläinen I, Avela J. Exhausting stretch-shortening cycle (SSC) exercise causes greater impairment in SSC performance than in pure concentric performance. Eur J Appl Physiol. 2003 Feb;88(6):527-34. doi: 10.1007/s00421-0020716-z. Epub 2002 Nov 27.

24. GOMES AC. Treinamento desportivo: estruturação e periodização. Porto Alegre: Artmed, 2002.

25. Diallo O, Dore E, Duche P, Van Praagh E. Effects of plyometric training followed by a reduced training programme on physical performance in prepubescent soccer players. J Sports Med Phys Fitness. 2001 Sep;41(3):342-8.

26. Wong PL, Chamari K, Wisløff U. Effects of 12week on-field combined strength and power training on physical performance among U-14 young soccer players. J Strength Cond Res. 2010 Mar;24(3):644-52. doi: 10.1519/JSC.0b013e3181 ad3349.

27. Dahab KS, McCambridge TM. Strength training in children and adolescents: raising the bar for young athletes? Sports Health. 2009 May;1(3):223-6. doi: $10.1177 / 1941738109334215$.

28. American Academy of Pediatrics Council on Sports Medicine and Fitness, McCambridge TM, Stricker PR. Strength training by children and adolescents. Pediatrics. 2008 Apr;121(4):835-40. doi: 10.1542/ peds.2007-3790.

Submission: February 16, 2021

Revision received: June 2, 2021 Accepted for publication: June 8, 2021 